Original Research Article

\title{
Effect of vitamin D on depression: an experimental study
}

\author{
Rohan Kolla, Suneel I. Majagi*
}

Department of Pharmacology, J. N. Medical College, Belgaum, Karnataka, India

Received: 11 May 2019

Accepted: 06 July 2019

\section{*Correspondence to:}

Dr. Suneel I. Majagi,

Email: suneelmajagi@yahoo. co.in

Copyright: (C) the author(s), publisher and licensee Medip Academy. This is an openaccess article distributed under the terms of the Creative Commons Attribution NonCommercial License, which permits unrestricted noncommercial use, distribution, and reproduction in any medium, provided the original work is properly cited.

\begin{abstract}
Background: There is a scarcity of studies regarding antidepressant activity of vitamin D in animals while there are some contradictory reports regarding the same in humans. Therefore the present study was planned to investigate the antidepressant effect of vitamin D and its interaction with standard antidepressant drugs in animals.

Methods: Forced swim test (FST) in adult male Wistar rats and tail suspension test (TST) in adult male Swiss albino mice were used to investigate antidepressant activity of vitamin D administered in single dose and multiple doses. Imipramine, a tri-cyclic antidepressant and fluoxetine, a selective serotonin reuptake inhibitor were used as standard antidepressant drugs. For interaction studies, half the therapeutic equivalent dose of vitamin $D$ was combined with sub-effective dose (SED) of imipramine or fluoxetine. Data was expressed as Mean \pm SD and analyzed by standard statistical tests. $\mathrm{P}<0.05=$ significant. Present study was ethically approved.

Results: Single dose administration of vitamin D did not show significant antidepressant effect either in FST or TST. Multiple dose administration of vitamin D showed significant antidepressant activity in TST but not in FST. Combination of vitamin D (half dose) with SED of either standard antidepressant drugs did not show any significant antidepressant activity. None of the treatment groups showed any significant difference on locomotor activity. Conclusions: In the present study, multiple dose administration of vitamin D showed some antidepressant activity. Further studies are needed to confirm and elaborate the role of vitamin D in behavioral disorders like depression.
\end{abstract}

Keywords: Animal, Depression, Interaction, Imipramine, Fluoxetine, Vitamin $\mathrm{D}$

\section{INTRODUCTION}

Mental illnesses or psychiatric diseases have afflicted mankind since its beginning. Psychiatric disorders have a majority contribution to morbidity and the economic burden. ${ }^{1}$ The global burden of psychiatric diseases is steadily on the rise. Mood disorders are among the commonest psychiatric disorders. World Health Organization estimates that major depression is the fourth most important cause of loss in disability-adjusted life years (DALYs). ${ }^{2}$ It is also estimated that by the year 2020, if the current trends continue, depression will be the second leading cause of DALYs, second only to ischemic heart disease. ${ }^{2}$
Depression is a state of low mood and aversion to activity that can affect a person's thoughts, behavior, feelings and sense of well-being. Recently depression is estimated to affect 350 million people and on average, about 1 in 20 people reported having an episode of depression in the previous year. ${ }^{3}$ Till now tricyclic antidepressants (TCAs), selective serotonin reuptake inhibitors (SSRIs) and certain newer atypical antidepressants have been the pharmacological options available for treating patients with depression. About one third of these patients do not respond primarily to antidepressant therapy. Those who do respond will progressively become resistant to treatment or show relapse. ${ }^{4}$ 
So there is an urgent need to evaluate novel treatment strategies to treat people with depression. Some studies suggest a link between vitamin D (1,25dihydroxycholecalciferol) and various mental disorders like depression. ${ }^{5,6}$ Higher incidence of seasonal affective disorder (SAD - a disorder characterized by depression, anxiety, irritability and fatigue) has been reported in winter when duration of exposure to sunlight is less leading to decreased production of vitamin D. ${ }^{5}$ Studies have indicated that vitamin D plays an important role in brain development and its function. ${ }^{7}$

If vitamin $\mathrm{D}$ shows considerable antidepressant activity then it may form a cost effective and easily affordable option in the fight against depression. There are some contradictory reports regarding vitamin D with respect to antidepressant activities in humans. However the literature survey indicates that there is a scarcity of studies regarding effect of supplementation of vitamin D on animal paradigms of depression. Hence the present study was planned to investigate the antidepressant effect of vitamin D as well as its interaction with sub-effective doses of standard antidepressant drugs in animals.

\section{Objectives}

Present experimental study was conducted to investigate antidepressant effect of vitamin D after single dose administration and after multiple dose administration and to assess the interaction between vitamin D and standard antidepressant drugs.

\section{METHODS}

Adult male Wistar rats weighing $175 \pm 25 \mathrm{~g}$ and adult male Swiss albino mice weighing $25 \pm 5 \mathrm{~g}$ were obtained from the central animal house of J. N. Medical College, Belgaum. They were acclimatized to 12:12 hour reversed light-dark cycle for 10 days before experimentation. They were maintained on standard chow pellet (Amrut brand) and water ad libitum.

\section{Drugs used and their dosages}

Various drugs like Imipramine (Tab. Antidep, Torrent Pharmaceuticals Ltd.), Fluoxetine (Cap. Fludep, Sun Pharmaceutical Industries Ltd), Calcitriol (Cap. Rocaltrol, Abbott Healthcare Pvt. Ltd) were obtained from the local pharmacy. Clinical doses of these drugs were converted into rat or mouse equivalent doses with help of the table devised by Paget and Barnes. ${ }^{8}$ Calculated doses were: imipramine $27 \mathrm{mg} / \mathrm{kg}$ in rat and $39 \mathrm{mg} / \mathrm{kg}$ in mouse, fluoxetine $7.2 \mathrm{mg} / \mathrm{kg}$ in rat and 10.4 $\mathrm{mg} / \mathrm{kg}$ in mouse, calcitriol $9 \mu \mathrm{g} / \mathrm{kg}$ in rat and $13 \mu \mathrm{g} / \mathrm{kg}$ in mouse.

Calculated doses of the drugs were uniformly mixed in the vehicle (1\% gum acacia) and the suspension was orally administered to the respective treatment group $(n=6)$ with the help of an appropriately sized gavage needle. Control groups received $0.5 \mathrm{ml}$ of $1 \%$ gum acacia. Drugs were given according to the following schedules:

- $\quad$ Single dose study: Single dose of different drugs were administered to the respective treatment groups $(\mathrm{n}=6$ in each group) prior to the experimentation. Only for the forced swim test, single dose administration was given three times i.e. 24 hour, 5 hour and 1 hour prior to the experimentation. ${ }^{9}$

- Multiple dose study: Calculated dose of different drugs were administered to the respective treatment groups ( $\mathrm{n}=6$ in each group) every 24 hours for 10 days at $8.00 \mathrm{AM}$ and the experiment was repeated on the $11^{\text {th }}$ day and data was collected.

\section{Tests for antidepressant activity}

Antidepressant activity was evaluated using forced swim test in Wistar rats and tail suspension test in Swiss albino mice.

Forced swim test (FST): The apparatus consists of a vertical Plexiglas cylinder measuring $40 \mathrm{~cm}$ in height and $18 \mathrm{~cm}$ in diameter. The apparatus was filled with water up to $15 \mathrm{~cm}$ and the temperature was maintained at 25 ${ }^{\circ} \mathrm{C}$. ${ }^{9,10}$ Rats were observed for 15 minutes. A rat was judged to be immobile when it ceased to struggle and remained floating motionless in the water making only those movements necessary to keep its head above the water. ${ }^{9,10}$

Tail suspension test (TST): The apparatus consists of two metallic rods connected with a horizontal rod. A nylon thread was suspended from its centre and a hook was attached to the free end of the nylon thread to enable suspension of the mice by their tail. Height of the horizontal rod was adjusted so that the snout of the mice was $58 \mathrm{~cm}$ from the base. ${ }^{9-11}$ A pretreated mouse was suspended from the hook hanging at the centre of the horizontal rod by an adhesive tape stuck $2 \mathrm{~cm}$ proximal to the tail tip. Immobile phase was recorded when the mouse stopped moving and hung motionless. Immobility time in seconds was recorded over a period of 6 min. ${ }^{9,10}$

\section{Sub-effective dose (SED) calculation and interaction studies}

To assess the sub-antidepressant dose, a series of experiments using decreasing dosages of the calculated antidepressant dose of vitamin D were planned. The maximum dosage showing insignificant effect on depression would have been selected as the subantidepressant dose. Since calcitriol did not show any antidepressant activity after single dose administration, it was decided to use half of the calculated therapeutic equivalent dose. For interaction studies, half the dose of calcitriol $(4.5 \mu \mathrm{g} / \mathrm{kg}$ in rats and $6.5 \mu \mathrm{g} / \mathrm{kg}$ in mice) was combined with sub-effective dose of imipramine (5 $\mathrm{mg} / \mathrm{kg}$ ) or sub-effective dose of fluoxetine $(5 \mathrm{mg} / \mathrm{kg}){ }^{11,12}$ 


\section{Locomotor activity}

Effect of all the drugs used in the present study on locomotor activity was tested by using the open field test. ${ }^{9,10}$ The apparatus is called the actophotometer and is a metal box measuring $68 \mathrm{~cm}$ in length, $68 \mathrm{~cm}$ in breadth and $45 \mathrm{~cm}$ in height. It is equipped with photocells sensitive to infrared light. ${ }^{9}$ The device electronically counts the number of times the infrared beams are interrupted by movement of the animal and this count is a measure of the locomotor activity. ${ }^{9,10}$

Present study was approved by the Institutional Animal Ethics Committee (IAEC) constituted as per the guidelines of Committee for the Purpose of Control and Supervision on Experiments on Animals (CPCSEA).

Data is expressed as Mean \pm SD. Data was analyzed by using one-way analysis of variance (ANOVA) followed by Bonferroni's multiple comparison test. Kruskal-Wallis test was used to analyze discrete values followed by Dunn's post hoc test. $\mathrm{P}<0.05$ was considered to be significant.

\section{RESULTS \\ Forced swim test in male Wistar rats}

In the single dose administration study, duration of immobility was significantly $(\mathrm{p}<0.05)$ decreased in Imipramine and Fluoxetine treatment groups when compared to that of control group. Therapeutic equivalent dose of calcitriol and combination of half the dose of calcitriol $(4.5 \mu \mathrm{g} / \mathrm{kg})$ with SED of Imipramine or SED of Fluoxetine did not show any significant difference when compared to that of control group (Table 1).

Table 1: Effect of single dose administration of various drugs in forced swim test.

\begin{tabular}{|c|c|c|c|c|c|c|}
\hline $\begin{array}{l}\text { Treatment groups } \\
(\mathrm{n}=6) \text { dose }(\mathrm{mg} / \mathrm{kg})\end{array}$ & $\begin{array}{l}\text { Control } \\
\text { (vehicle) }\end{array}$ & $\begin{array}{l}\text { Imipramine } \\
(27)\end{array}$ & $\begin{array}{l}\text { Fluoxetine } \\
\text { (7.2) }\end{array}$ & $\begin{array}{l}\text { Calcitriol } \\
(9)\end{array}$ & $\begin{array}{l}\text { SED of } \\
\text { imipramine (5) } \\
+ \text { half dose of } \\
\text { calcitriol }(4.5)\end{array}$ & $\begin{array}{l}\text { SED of } \\
\text { fluoxetine }(5)+ \\
\text { half dose of } \\
\text { calcitriol }(4.5)\end{array}$ \\
\hline $\begin{array}{l}\text { Immobility time in } \\
\text { seconds (Mean } \pm \text { SD) }\end{array}$ & $123.70 \pm 25.44$ & $85.17^{*} \pm 13.64$ & $87.33^{*} \pm 20.58$ & $99.67 \pm 22.08$ & $92.33 \pm 16.08$ & $92.00 \pm 8.17$ \\
\hline
\end{tabular}

ANOVA followed by Bonferroni's multiple comparison test. ${ }^{*} \mathrm{P}<0.05$ as compared to control group.

Table 2: Effect of single dose administration of various drugs in tail suspension test.

\begin{tabular}{|c|c|c|c|c|c|c|}
\hline $\begin{array}{l}\text { Treatment groups } \\
(\mathrm{n}=6) \text { dose }(\mathrm{mg} / \mathrm{kg})\end{array}$ & $\begin{array}{l}\text { Control } \\
\text { (vehicle) }\end{array}$ & $\begin{array}{l}\text { Imipramine } \\
(27)\end{array}$ & $\begin{array}{l}\text { Fluoxetine } \\
(7.2)\end{array}$ & Calcitriol (9) & $\begin{array}{l}\text { SED of } \\
\text { imipramine (5) } \\
+ \text { half dose of } \\
\text { calcitriol }(4.5)\end{array}$ & $\begin{array}{l}\text { SED of } \\
\text { fluoxetine }(5)+ \\
\text { half dose of } \\
\text { calcitriol }(4.5)\end{array}$ \\
\hline $\begin{array}{l}\text { Immobility time in } \\
\text { seconds (Mean } \pm \text { SD) }\end{array}$ & $220.20 \pm 17.28$ & $170.00 * \pm 21.57$ & $169.50 * \pm 29.62$ & $207.70 \pm 17.14$ & $214.20 \pm 25.87$ & $211.80 \pm 28.51$ \\
\hline
\end{tabular}

ANOVA followed by Bonferroni's multiple comparison test. ${ }^{*} \mathrm{P}<0.05$ as compared to control group.

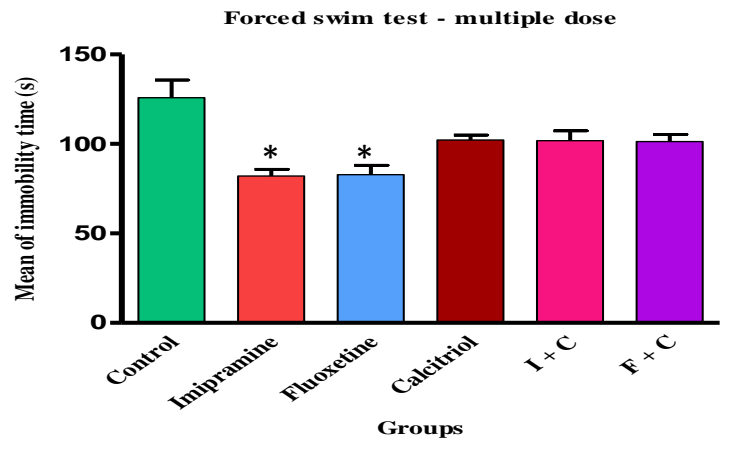

Figure 1: Effect of multiple dose administration of various drugs in forced swim test.

Data expressed as Mean \pm SD, ANOVA followed by Bonferroni's multiple comparison test, ${ }^{*} \mathrm{p}<0.001$ as compared to control. I -sub-effective dose of imipramine, F-Sub-effective dose of fluoxetine, C-half dose of calcitriol $(4.5 \mu \mathrm{g} / \mathrm{kg})$.
In the multiple dose study, only imipramine and fluoxetine treatment groups showed significant $(\mathrm{p}<0.001)$ decrease in the immobility time when compared to that of control group. Therapeutic equivalent dose of calcitriol and combination of half the dose of calcitriol $(4.5 \mu \mathrm{g} / \mathrm{kg})$ with SED of imipramine or SED of fluoxetine treatments did not show any significant difference when compared to that of control group (Figure 1).

\section{Tail suspension test in male Swiss albino mice}

After single dose administration, Imipramine and Fluoxetine treatment groups produced significant $(\mathrm{p}<0.05)$ decrease in immobility time when compared with that of control group. Therapeutic equivalent dose of calcitriol and combination of half the dose of calcitriol $(4.5 \mu \mathrm{g} / \mathrm{kg})$ with SED of imipramine or SED of fluoxetine did not show any significant difference when compared to that of control group (Table 2). 
In the multiple dose study, imipramine, fluoxetine and calcitriol treatment groups showed significant $(p<0.01$ and $\mathrm{p}<0.001)$ decrease in immobility time when compared to that of vehicle treated (control) group. Calcitriol treatment group did not show any significant difference in immobility time when compared to that of Imipramine and Fluoxetine treatment groups indicating similar activity (Figure 2).

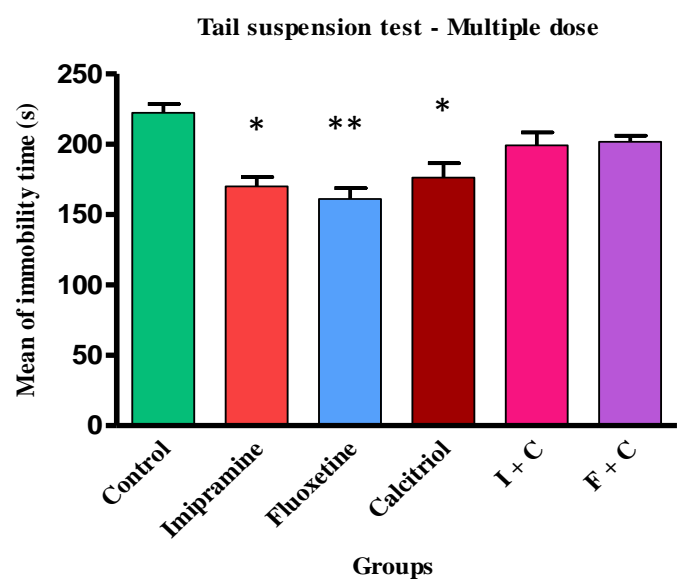

Figure 2: Effect of multiple dose administration of various drugs in tail suspension test.

Data expressed as Mean \pm SD, ANOVA followed by Bonferroni's multiple comparison test, ${ }^{*} p<0.01, * * p<0.001$ as compared to control. I-Sub-effective dose of Imipramine, Fsub-effective dose of fluoxetine, $\mathrm{C}$-half dose of calcitriol $(4.5$ $\mu \mathrm{g} / \mathrm{kg})$.

\section{Locomotor activity}

No significant difference was noticed in the actophotmeter count among the various treatments groups when compared with that of vehicle treated control group (Figure 3).

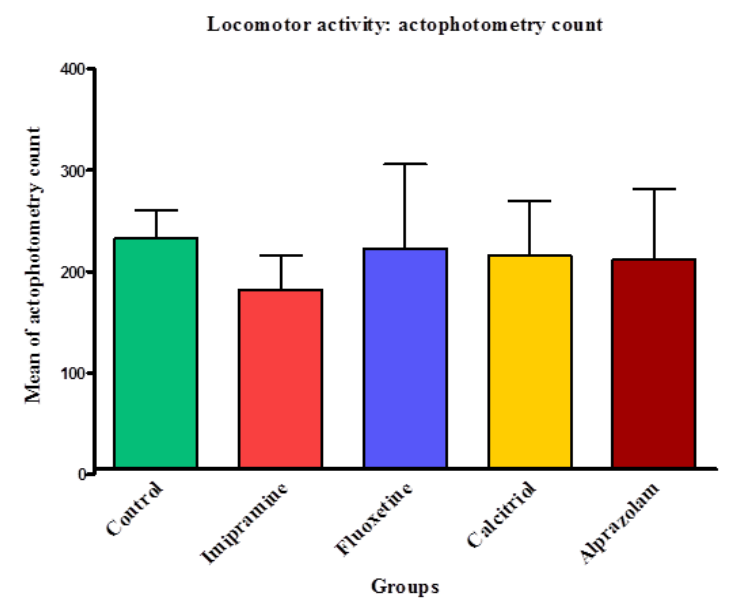

Figure 3: Effect of various treatments on locomotor activity.

Data expressed as Mean \pm SD, ANOVA: $p>0.05$ indicating homogeneity among the different treatment groups.

\section{DISCUSSION}

Single dose administration of vitamin D did not show any significant antidepressant action in both forced swim test and tail suspension tests. Whereas, after multiple dose administration, vitamin $\mathrm{D}$ showed significant $(\mathrm{p}<0.01)$ increase in immobility time when compared with that of control group, only in the tail suspension test but not in the forced swim test. In the tail suspension test there was no significant difference between the imipramine and calcitriol treatment groups indicating similar activity.

Apparent difference in the results of FST and TST found in the present study may be due to many reasons. There are a few fundamental differences between FST and TST, even though both paradigms are used for antidepressant activity are based on the principle of behavioral despair. ${ }^{9,10}$ Main differences between FST and TST are: (1) The immersion, which is necessary to produce the 'behavioural despair', may induce hypothermia in animals. This is avoided in tail suspension test. (2) Recording of an objective measure in the TST might be more precise than the appreciation of immobility in the FST, i.e. there is clear differentiation between the immobile and mobile phases in TST. (3) TST is more sensitive to lower doses of drug and provides a clearer dose effect relationship. ${ }^{13,14}$

Differences have also been noted in the behavioural effects of antidepressant drugs on different rat strains in the rat FST. ${ }^{9,15}$ Similarly differences in the TST among eleven inbred strains of mice have been reported regarding basal immobility. ${ }^{16}$ A study has reported discordant results in FST and TST, in which mice with a deficient serotonin transporter gene showed markedly increased immobility in the FST, but immobility was reduced in the TST. ${ }^{17}$ In another study, nicotine was shown to have effect only in FST whereas there was no effect on TST. ${ }^{15}$

There are contradictory reports regarding effect of Vitamin D on depression in human beings. Some epidemiological studies have reported positive correlation between vitamin $\mathrm{D}$ deficiency and depression. ${ }^{18,19}$ Deficiency might be nutritional or due to reduced exposure to sun leading to decreased production of vitamin $\mathrm{D}$ in the skin. One example is the seasonal affective disorder (SAD), a subtype of depression, incidence of which increases with latitude and thus reduced sun exposure. ${ }^{20}$ Vitamin D when given in high doses and/or for a long period of time it can improve the depression scores. ${ }^{21}$ Where as some studies have found no correlation between vitamin $\mathrm{D}$ administration and mood disorders and also excessive vitamin D supplementation may also have negative effects. ${ }^{8,22}$

Interaction studies using sub-effective doses were conducted to investigate if vitamin D has any potentiating effects on the antidepressant activity of the standard antidepressants drugs. However when half the therapeutic 
equivalent dose of vitamin $\mathrm{D}$ was combined with subeffective doses of either Imipramine or Fluoxetine, it did not show any significant change in the immobility times both in FST and TST.

Literature search suggests that there is a scarcity of animal studies which have used vitamin D as an intervention in animal paradigms of depression. Literature survey also suggests a lacuna of interaction studies involving vitamin D along with standard antidepressant drugs. Significant decrease in immobility time in tail suspension test after multiple dose administration of vitamin $\mathrm{D}$ provides a clue that it has some role to play in depression if it is administered for a longer duration.

Vitamin D acts by binding to its receptors which further bind to a VDRE (vitamin D response element). This causes changes in expression of the target genes. ${ }^{23}$ These changes in gene expression may take much longer time to come into effect. ${ }^{18,19}$ Vitamin D is stored in the adipose tissue for long periods of time and released slowly into circulation. ${ }^{24}$ These reports may explain the mechanism for the response seen in the present study after multiple dose administration of vitamin D.

Decrease in immobility time in rodents in tail suspension test predicts that the drug can decrease depressive symptoms in clinical settings. ${ }^{25}$ Collocation of vitamin D receptors in certain areas of brain have shown to be involved in pathogenesis of depression. ${ }^{18,19,26}$ Vitamin D deprivation resulted in decreased levels of nerve growth factor (NGF) and glial cell-line derived neurotrophic factor (GDNF) and both have been associated with depression. ${ }^{18,19,27,28}$

In the present study, experiments showed no significant difference between the locomotor activities of the drugs used, ruling out any influence of the drugs on locomotor system which in turn can affect the immobility in antidepressant tests.

In the present study, administration of multiple doses of vitamin D has shown antidepressant activity in the tail suspension test. Further research has to be carried out to confirm the role of vitamin D in depression and the underlying mechanism.

\section{CONCLUSION}

In the present study, vitamin D was evaluated for its antidepressant activities using different animal models of depression viz., FST and TST. Administration of single dose of vitamin D did not show any antidepressant effect whereas multiple dose administration of vitamin D showed significant antidepressant activity only in tail suspension test. In interaction studies, vitamin D in half the therapeutic equivalent dose did not show any significant antidepressant activity when it was combined with sub-effective doses of standard antidepressant drugs both in single dose and multiple dose studies. Further studies are needed to confirm and elaborate the role of vitamin $\mathrm{D}$ in behavioural disorders like depression.

Funding: No funding sources

Conflict of interest: None declared

Ethical approval: The study was approved by the Institutional Ethics Committee

\section{REFERENCES}

1. Jacob KS. Depression: a major public health problem in need of a multi-sectoral response. Indian $\mathrm{J}$ Med Res. 2012;136(4):537-9.

2. Grover S, Dutt A, Avasthi A. An overview of Indian research in depression. Indian $\mathbf{J}$ Psychiatry. 2010;52(1):178-88.

3. Marcus M, Yasamy MT, van Ommeren M, Chisholm D, Saxena S. Depression: A Global Public Health Concern. NZ: World Mental Health Federation. 2012: 6-8

4. Fava M, Davidson KG. Definition and epidemiology of treatment-resistant depression. Psychiatr Clin North Am. 1996;19(2):179-200.

5. Stumpf WE, Privette TH. Light, vitamin D and psychiatry. Role of 1,25 dihydroxyvitamin D3 (soltriol) in etiology and therapy of seasonal affective disorder and other mental processes. Psychopharmacology (Berl). 1989;97(3):285-94.

6. Hoogendijk WJ, Lips P, Dik MG, Deeg DJ, Beekman AT, Penninx BW. Depression is associated with decreased 25-hydroxyvitamin $\mathrm{D}$ and increased parathyroid hormone levels in older adults. Arch Gen Psychiatry. 2008;65(5):508-12.

7. Kalueff AV, Lou YR, Laaksi I, Tuohimaa P. Increased anxiety in mice lackingvitamin $\mathrm{D}$ receptor gene. Neuroreport. 2004;15(8):1271-4.

8. Dumville JC, Miles JN, Porthouse J, Cockayne S, Saxon L, King C. Can vitamin D supplementation prevent winter-time blues? A randomised trial among older women. J Nutr Health Aging. 2006;10(2):151-3

9. Vogel HG. Drug discovery \& Evaluation: Pharmacological assays. 3rd ed. New York: Springer; 2008.

10. Gupta SK. Drug screening methods (Preclinical evaluation of new drugs). 2nd ed. Chapter 27, Antidepressant Drugs. New Delhi: Jaypee Brothers Medical Publishers Limited; 2009: 392-399.

11. Castagné V, Moser P, Roux S, Porsolt RD. Rodent models of depression: forced swim and tail suspension behavioral despair tests in rats and mice. Chapter 8: Unit 8.10A. Curr Protoc Neurosci. 2011.

12. Gehlert DR, Rasmussen K, Shaw J, Li X, Ardayfio P, Craft L, et al. Preclinical evaluation of melaninconcentrating hormone receptor 1 antagonism for the treatment of obesity and depression. J Pharmacol Exp Ther. 2009;329(2):429-38.

13. Carlezon WA Jr, Mague SD, Parow AM, Stoll AL, Cohen BM, Renshaw PF. Antidepressant-like effects of uridine and omega-3 fatty acids are potentiated by 
combined treatment in rats. Biol Psychiatry. 2005;57(4):343-50.

14. Bhattacharya SK, Satyan KS, Ramanathan M. Experimental methods for evaluation of psychotropic agents in rodents: II-Antidepressants. Indian J Exp Biol. 1999;37(2):117-23.

15. Andreasen JT, Redrobe JP. Antidepressant-like effects of nicotine and mecamylamine in the mouse forced swim and tail suspension tests: role of strain, test and sex. Behav Pharmacol. 2009;20(3):286-95.

16. Liu X, Gershenfeld HK. Genetic differences in the tail-suspension test and its relationship to imipramine response among 11 inbred strains of mice. Biol Psychiatry. 2001;49(7):575-81.

17. Holmes A, Yang RJ, Murphy DL, Crawley JN. Evaluation of antidepressant-related behavioral responses in mice lacking the serotonin transporter. Neuropsychopharmacology. 2002;27(6):914-23.

18. McCann JC, Ames BN. Is there convincing biological or behavioral evidence linking vitamin D deficiency to brain dysfunction? FASEB J. 2008;22(4):982-1001.

19. Bertone-Johnson ER. Vitamin D and the occurrence of depression: causal association or circumstantial evidence? Nutr Rev. 2009;67(8):481-92.

20. Lurie SJ, Gawinski B, Pierce D, Rousseau SJ. Seasonal affective disorder. Am Fam Physician. 2006;74.

21. Mozaffari-Khosravi H, Nabizade L, YassiniArdakani SM, Hadinedoushan H, Barzegar K. The effect of 2 different single injections of high dose of vitamin $\mathrm{D}$ on improving the depression in depressed patients with vitamin $\mathrm{D}$ deficiency: a randomized clinical trial. J Clin Psychopharmacol. 2013;33(3):378-85.

22. Jorde R, Strand Hutchinson M, Kjærgaard M, Sneve M, Grimnes G. Supplementation with high doses of vitamin D to subjects without vitamin D deficiency may have negative effects: pooled data from four intervention trials in Troms $\varnothing$. ISRN Endocrinol. 2013;2013:348705.

23. Murray R, Benderm D, Botham KM, Kennelly PJ, Rodwell V, Weil PA. Harper's illustrated Biochemistry, 29th ed. Newyork. McGraw Hill Professional, 2012. Chapter 44. Micronutrients vitamins and minerals; 2012.

24. Sweetman S, editor. Martindale: The complete drug reference. 36th ed. London: Pharmaceutical Press; 2009.

25. Walf AA, Frye CA. The use of the elevated plus maze as an assay ofanxiety-related behavior in rodents. Nat Protoc. 2007;2(2):322-8.

26. Eyles DW, Smith S, Kinobe R, Hewison M, McGrath JJ. Distribution of the vitamin $\mathrm{D}$ receptor and 1 alpha-hydroxylase in human brain. $\mathrm{J}$ Chem Neuroanat. 2005;29(1):21-3.

27. Féron F, Burne TH, Brown J, Smith E, McGrath JJ, Mackay-Sim A, et al. Developmental Vitamin D3 deficiency alters the adult rat brain. Brain Res Bull. 2005;65(2):141-8.

28. Duman RS. Neurotrophic factors in etiology and treatment of mood disorders. In: Sibley RD, Hanin I, Kuhar M, Skolnick P, editors. Handbook of contemporary neuropharmaoclogy. London: John Wiley \& Sons, Inc; 2007: 789-820.

Cite this article as: Kolla R, Majagi SI. Effect of vitamin D on depression: an experimental study. Int J Basic Clin Pharmacol 2019;8:2033-8. 